\title{
Penggunaan Teknologi Flutter dalam Aplikasi Mobile Untuk Pengembangan Kedai Kopi
}

\author{
Budi Sudrajat \\ Universitas Bina Sarana Informatika \\ J1. Kramat Raya No.98, Senen, Jakarta Pusat 10450 \\ budi.bst@bsi.ac.id
}

\begin{abstract}
Diajukan : 02 / September / 2021
Disetujui : : 22/September / 2021

Dipublikasi : $01 /$ Oktober / 2021
\end{abstract}

\begin{abstract}
ABSTRAK
Kedai kopi merupakan tempat untuk para penikmat kopi dan juga sebagai tempat bersantai bersama teman yang lainnya. Namun dimasa pandemi covid-19 seperti saat ini, hal tersebut sudah sangat sulit dilakukan. Hal ini diakibatkan karena adanya aturan untuk tidak berkumpul dan berkerumun. Dengan begitu para pemilik kedai kopi mendapatkan efek yang cukup signifikan akibat sepinya para pelanggan. Untuk itu perlu dibuat sebuah aplikasi yang bisa membantu dalam memberikan pelayanan kepada para penikmat kopi. Situasi ini membuat para pemilik kedai kopi harus mencari terobosan untuk menaikan pendapatan mereka, salah satunya melalui penjualan secara online khususnya dengan menggunakan perangkat mobile. Aplikasi ini akan menjembatani antara para pemilik kedai kopi dengan para penikmat kopi dalam transaksi dimasa pandemi saat ini. Aplikasi yang dibangun berbasis mobile dengan sistem operasi android untuk pengguna. Metode yang digunakan dalam penyusunan penelitian ini menggunakan model Waterfall. Sistem aplikasi ini menggunakan Android Studio dan Visual Studio Code sebagai Integrated Development Environment (IDE) serta XAMPP sebagai bundle untuk web server (Apache) dan database (MySQL) dengan tools Unified Modelling Language (UML). Aplikasi ini bisa membantu bagi para pemilik kedai kopi untuk memberikan informasi mengenai produk yang dijualnya juga promo serta diskon yang ada dan penikmat kopi bisa tetap menikmati kopi karena adanya kemudahan dalam mengakses aplikasi.
\end{abstract}

Keywords: android, aplikasi, kedai kopi, pandemi, waterfall

\section{PENDAHULUAN}

Pandemi covid-19 membawa efek kepada semua kegiatan bisnis, termasuk juga kedai kopi yang kerap menjadi tempat kongko generasi millennial dan lainnya. Berkaitan dengan adanya aturan yang ketat mengenai kerumunan orang, membuat banyak tempat usaha tidak boleh menyediakan tempat berkumpul. Begitu juga dengan kedai kopi,dan imbasnya bisa diketahui bersama, pendapatan atau penjualan kedai kopi menurun drastis. Situasi ini membuat para pemilik kedai kopi harus mencari terobosan untuk menaikan pendapatan mereka, salah satunya melalui penjualan secara online khususnya dengan menggunakan perangkat mobile.. Kini teknologi telah berkembang pesat dan semakin canggih seiring dengan perkembangan zaman sehingga terjadi penambahan fungsi teknologi yang semakin memanjakan kehidupan manusia. Salah satu contoh fasilitas canggih saat ini adalah gadget. Di awal kemunculannya, gadget hanya dimiliki oleh kalangan tertentu yang benar-benar membutuhkannya demi kelancaran pekerjaan mereka. Kini gadget bukan lagi sekedar alat berkomunikasi, tetapi gadget juga merupakan alat untuk mencipta dan mnghibur dengan suara, tulisan, gambar dan video. Sekarang manusia berlomba-lomba untuk memiliki gadget karena gadget bukan hanya merupakan alat berkomunikasi, namun juga bagi masyarakat pada umumnya gadget sekaligus sebagai lifestyle (gaya hidup), tren, 
dan prestise (Marpaung, 2018). Hal ini menjadi peluang para produsen handphone untuk membuat alat bantu komunikasi yang praktis dan fleksibel yaitu smartphone. Khususnya pada smartphone berbasis android yang opensource bagi pengembang untuk menciptakan ataupun mengembangkan aplikasi-aplikasi baru. Di era yang serba digital seperti saat ini, memiliki sebuah smartphone merupakan sebuah kebutuhan. Tanpa smartphone, orang akan mengalami kesusahan dalam berkomunikasi. Salah satu produsen smartphone di Indonesia adalah Xiaomi. Xiaomi merupakan perusahaan elektronik yang berasal dari Cina dan berkantor pusat di Beijing. Xiaomi didirikan pada 6 April 2010 dan merilis smartphone pertamanya di bulan Agustus 2011 (Kamila, Suharyono, \& Nuralam, 2019). Keberadaan smartphone sangat membantu para pengguna untuk mendapatkan informasi dan memenuhi kebutuhannya dengan lebih cepat dan mudah, termasuk dalam hal pengembangan usaha kedai kopi.

Di era saat ini kedai kopi merupakan sebuah rumah nyaman tempat kita menikmati beberapa cangkir kopi kesukaan. Tren bisnis kedai kopi berubah akibat pandemi covid19, adanya pembatasan sosial selama pandemi membuat kedai kopi tidak lagi dikunjungi sebagai tempat pertemuan atau lokasi bekerja. Dengan keadaan demikian maka para pemilik kedai sangat membutuhkan aplikasi mobile agar usaha mereka tetap berjalan dimasa pandemi ini. Dengan adanya aplikasi mobile diharapkan para pelanggan masih bisa menikmati kopi kesukaannya dengan memesan secara online.

\section{STUDI LITERATUR Penelitian Terdahulu}

Kopi tidak hanya berperan penting sebagai sumber devisa melainkan juga merupakan sumber penghasilan bagi tidak kurang dari satu setengah juta jiwa petani kopi di Indonesia. Kopi telah menjadi produk minuman yang digemari oleh berbagai kalangan masyarakat, mulai dari petani, buruh, mahasiswa hingga elit-elit politik.Dalam kehidupan keseharian selain menyajikan rasa nikmat yang khas, kopi juga menjadi salah satu minuman yang cocok untuk aktivitas manusia mulai dari sarapan, bersantai, bekerja, istirahat, berdiskusi, atau sekedar berbincang-bincang dengan teman selalu di damping dengan kopi (Maryani, ROCHDIAN, \& SETIA, 2020). Flutter adalah SDK untuk pengembangan aplikasi mobile yang dikembangkan oleh Google untuk membangun antarmuka (user interface) aplikasi android dan iOS. Rilis pada juni 2018 sama seperti react native, framework ini dapat digunakan untuk membuat atau mengembangkan aplikasi mobile yang dapat berjalan pada device iOS dan Android. Dibuat menggunakan bahasa $\mathrm{C}, \mathrm{C}++$, Dart and Skia membuat Flutter ini menjadi salah satu framework yang sangat menarik dan worth untuk di pelajari. Hal yang menarik pada framework ini adalah semua kode di compile dalam kode native nya (Android NDK, LLVM, AOT-compiled) tanpa ada intrepeter pada prosesnya sehingga proses compile-nya menjadi lebih cepat. Dari segi penulisan kodenya, Flutter ini sangat berbeda dari react native dan lebih cenderung mendekati Java Android jadi untuk developer react native agak sedikit kesulitan untuk memahami kode pada Flutter ini. Untuk membuat aplikasi Flutter, diperlukan untuk mengerti bahasa Dart. Dart merupakan bahasa pemrograman yang dibuat oleh Google untuk menggantikan Javascript. Dart menggunakan static typing yang berarti sebelum memakai variabel, variabel perlu didefinisikan terlebih dahulu. Dart bisa berjalan pada semua perangkat juga, pada web Dart memakai dart2js yang artinya Dart diubah ke Javascript agar bisa dimengerti browser. Pada perangkat desktop Dart memakai dart2aot yang mengubah Dart menjadi bahasa mesin. Pada perangkat mobile Dart memakai Flutter. Syntax pada bahasa Dart sangat mudah dipelajari, karena Dart memiliki kemiripan dengan syntaxsyntax pemrograman lain, seperti Javascript dan Java (Chandra \& Tjandra, 2020). Seiring berkembangnya teknologi informasi, penggunaan internet dan smartphone semakin bertambah. Hal ini membuat perkembangan bisnis online atau $e$ commerce semakin berkembang pesat. Persaingan di bidang ini semakin ketat karena dapat memudahkan orang dalam melakukan transaksi penjualan dan 
pembelian serta dapat memperluas jangkauan bisnis tersebut. Paper Factory merupakan wirausaha yang menjual paper craft yang dapat di design dengan muka sendiri. Paper Factory belum memiliki web online shop agar dapat jual beli secara online (Kelvin, 2016). Penelitian dengan judul Strategi Pengembangan Bisnis Kedai Kopi“AI COFFEE" Di Desa Pakemitan Kecamatan Ciawi Kabupaten Tasikmalaya yang berkaitan dengan strategi bisnis dalam masa pandemi covid-19 merupakan topik yang baru, penelitian tentang strategi manajemen bisnis pasca pandemi COVID19 bagi pelaku UMKM di Kabupaten Sumbawa. Hasil penelitian menjelaskan bahwa strategi manajemen bisnis pasca covid-19 bagi pelaku UMKM dapat memberikan peningkatan dan pengembangan keberlanjutan usaha yang baik dengan menerapkan penguatan di bidang pemasaran, SDM, keuangan dan operasional sebagai langkah strategis untuk menciptakan eksistensi usaha yang efektif dan efisien (Fitriyani, Sudiyarti, \& Fietroh, 2020)

Terkait dengan penelitian, penelitian yang berjudul "Sistem Informasi Pemesanan Tiket Travel Berbasis Mobile Android". Aplikasi ini dapat menampilkan jadwal keberangkatan travel pada kasus Rahayu Travel dari Selorejo - Blitar. Pemesanan dengan memilih tanggal berangkat, rute awal dan tujuan. Setelah itu kode pemesanan diberikan untuk mengecek status pembayaran dan rincian keberangkatan pemesan, jika sudah dibayar maka status pembayaran akan menjadi lunas. Manfaat dari penelitian ini yaitu dapat memberikan kemudahan dan kenyamanan dalam pemesanan tiket travel pada Rahayu Travel (Krisnada \& Tanone, 2019).

Penelitian untuk Sistem Informasi Indekos Berbasis Android, untuk mempercepat pencarian tempat kost yang memiliki kualitas yang baik dan layak untuk digunakan oleh masyarakat umum dan juga sangat bermanfaat bagi pengguna kost yang akan mencari atau melihat tempat kost di Purwokerto (Gunawan \& Saputro, 2017).

Penelitian lainnya yang berjudul "Pengembangan Sistem Informasi Akademik Berbasis Android Menggunakan Flutter Di Politeknik". Sistem Informasi
Akademik Politeknik Sahid pada saat ini hanya menggunakan power builder appeon, dengan dibuatnya aplikasi berbasis android membantu mahasiswa mudah dalam mengakses informasi akademik serta memudahkan mahasiswa mendapatkan informasi terbaru tanpa harus berada dilingkungan kampus. Interface yang disajikan berupa jadwal kuliah, transkrip nilai, record akademik setiap mahasiswa, menghadirkan informasi terbaru, dan mencari daftar dosen yang ada pada android device (Hakim, Harefa, \& Widodo, 2019).

\section{METODE}

Dalam penelitian ini penulis menggunakan beberapa metodologi penelitian dengan studi kepustakaan untuk mengembangkan perangkat lunak ini, penulis mencari literatur atau sumber pustaka yang berhubungan dengan perangkat lunak yang akan dibuat. Sumber pustaka ini akan membantu penulis dalam penulisan teori-teori yang ada, serta dapat digunakan sebagai pembanding dengan penelitian yang telah dibuat. Kemudian menggunakan metode observasi, yang dilakukan untuk mengumpulkan data dengan mengadakan pengamatan langsung di lapangan, kemudian melakukan pencatatan secara sistematis terhadap objek. Mengamati keseluruhan aspek yang bersesuaian dengan kebutuhan pembuatan aplikasi. Setelah dilakukan observasi dan pengumpulan data maka akan melakukan metode pengembangan perangkat lunak, metode yang digunakan dalam membuat proyek ini adalah dengan metode waterfall. Model Waterfall SDLC adalah proses pembangunan software secara berurutan di mana kemajuan pembangunan software seperti aliran mengalir semakin ke bawah (mirip dengan air terjun) melalui daftar tahapan yang harus dijalankan untuk berhasil membangun sebuah perangkat lunak komputer. Awalnya, model air terjun diusulkan oleh Winston W. Royce pada tahun 1970 untuk menggambarkan praktek rekayasa perangkat lunak. Model Waterfall mendefinisikan beberapa berturut-turut tahapan yang harus diselesaikan satu demi satu dan bergerak ke tahap berikutnya hanya ketika fase sebelumnya telah benar-benar 
dilakukan. Gambar 2 menggambarkan fase dari Model SDLC Waterfall (Sukamto \& Salahuddin, 2016).

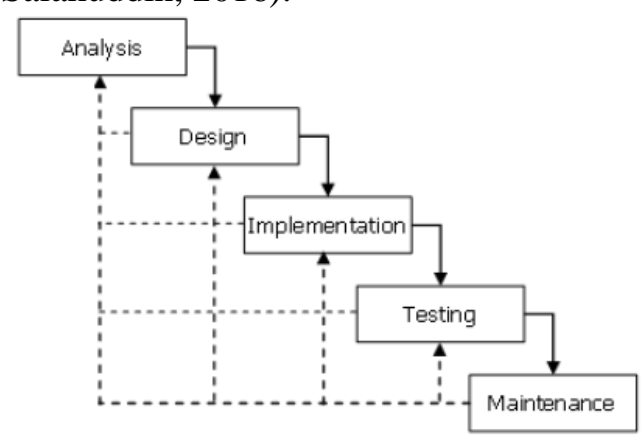

Gambar 1. Ilustrasi Model Waterfall

Pada tahapan analisis ini penulis mengumpulkan informasi dan menganalisa kebutuhan sistem yang akan dikerjakan. Proses pengumpulan data dilakukan dengan cara wawancara yang dilakukan terhadap pemilik kedai kopi dan para pelanggan. Tahap desain merupakan pengolahan informasi dan analisa kebutuhan sistem, hasil analisa selanjutnya dibuat desain sistem yang akan digunakan untuk mengatasi masalah yang timbul. Untuk menggambarkan sistem seperti apa yang akan dibuat, maka perlu dibuat desain pemodelan menggunakan UML (Unified Modeling Language) untuk aplikasi android yang meliputi Use Case Diagram, Activity Diagram dan Sequence Diagram. Metode tersebut merupakan informasi yang cukup bagi pembaca untuk mengikuti alur penelitian dengan baik sehingga pembaca yang akan mengkaji atau mengembangkan penelitian serupa memperoleh gambaran tentang langkah-langkah penelitian tersebut. Bagian ini, populasi dan sampel, variabel penelitian operasional, data yang digunakan (jenis dan sumber), teknik pengumpulan data, dan teknik analisis data (model analysis).

\section{HASIL DAN PEMBAHASAN}

Langkah selanjutnya dengan melakukan analisa untuk merumuskan analisa kebutuhan pengguna sebagai dasar panduan untuk memberikan solusi terhadap permasalahan yang ada. Untuk analisa kebutuhan antara lain : Merancang aplikasi mobile dimana para pelanggan kedai kopi bisa dengan mudah mendapatkan informasi produk dan juga pelanggan bisa mendapatkan kupon untuk mendapatkan promo maupun diskon, Merancang aplikasi mobile untuk para pelanggan dengan mudah memilih menu kopi yang diinginkan serta menukarkan kupon promo maupun diskon yang dimiliki, Merancang aplikasi mobile secara cepat dan efisien, selain memberikan informasi produk, promo maupun diskon juga dapat menampilkan riwayat promo maupun diskon yang sudah digunakan. Hasil dari perumusan analisa yang dilakukan penulis menjadi dasar untuk membuat rancangan sebuah aplikasi mobile dengan menggunakan teknologi flutter dan menjadi solusi bagi para pemilik kedai kopi dalam memasarkan produk yang dijual. Untuk dapat menghasilkan sistem informasi yang baik dan berkualitas, maka diperlukan prosedur-prosedur rancangan yang dengan siklus pengembangan sistem informasi atau Software Development Life Cylcle (SDLC). Untuk rancangan aplikasi penulis menggunakan permodelan Unified Modeling Language (UML). Use Case Diagram menggambarkan hubungan antar user dengan proses dan proses-proses yang terjadi di dalam aplikasi. Berikut usecase yang digunakan untuk aplikasi pengembangan kedai kopi :

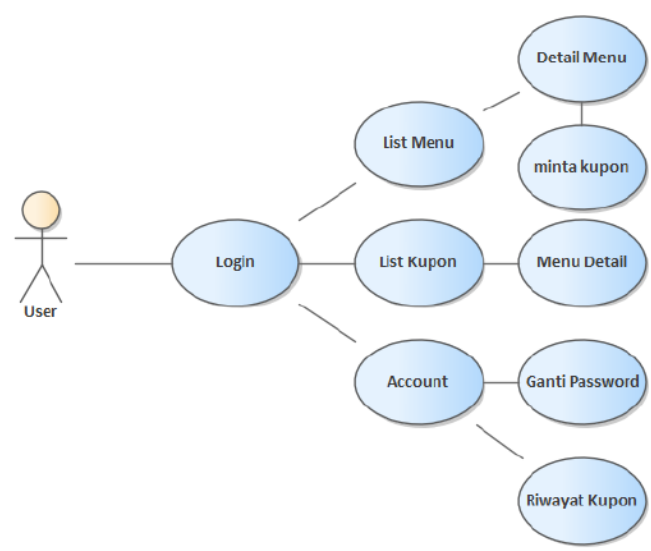

Gambar 2. Use Case Diagram

Usecase diagram diatas bisa dijelaskan dalam tabel yang ada dibawah ini :

Tabel 1. Case Home

\begin{tabular}{|l|l|}
\hline \multicolumn{1}{|c|}{ Nama Case } & \multicolumn{1}{c|}{ Case Home } \\
\hline Skenario & User memilih Home \\
\hline Deskripsi & $\begin{array}{l}\text { user memilih icon } \\
\text { yang ada di main } \\
\text { menu aplikasi mobile }\end{array}$ \\
\hline Aksi & Memilih button yang \\
\hline
\end{tabular}




\begin{tabular}{|l|l|}
\hline & ada \\
\hline Persyaratan & $\begin{array}{l}\text { Sudah menginstall } \\
\text { aplikasi }\end{array}$ \\
\hline Kondisi Akhir & $\begin{array}{l}\text { Menu berhasil } \\
\text { ditampilkan }\end{array}$ \\
\hline
\end{tabular}

Tabel 2. Case Kupon

\begin{tabular}{|l|l|}
\hline \multicolumn{1}{|c|}{ Nama Case } & \multicolumn{1}{c|}{ Case Kupon } \\
\hline Skenario & User memilih kupon \\
\hline Deskripsi & $\begin{array}{l}\text { User melakukan } \\
\text { swipe up dibagian } \\
\text { bawah layar menu } \\
\text { home. }\end{array}$ \\
\hline Aksi & Swipe up list menu \\
\hline Persyaratan & $\begin{array}{l}\text { Aplikasi sudah } \\
\text { ready, } \text { user } \text { sudah } \\
\text { berada di home. }\end{array}$ \\
\hline Kondisi Akhir & Menu ditampilkan. \\
\hline
\end{tabular}

Tabel 3. Case Menu

\begin{tabular}{|l|l|}
\hline \multicolumn{1}{|c|}{ Nama Case } & \multicolumn{1}{c|}{ Case Menu } \\
\hline Skenario & User memilih Menu \\
\hline Deskripsi & $\begin{array}{l}\text { User menekan } \\
\text { tombol menu pada } \\
\text { bagian navigation } \\
\text { bar. }\end{array}$ \\
\hline Aksi & Pilih tombol menu \\
\hline Persyaratan & $\begin{array}{l}\text { Aplikasi sudah } \\
\text { ready, } \text { user } \text { sudah } \\
\text { berada di home. }\end{array}$ \\
\hline Kondisi akhir & List menu muncul. \\
\hline
\end{tabular}

Activity Diagram biasa untuk mendokumentasikan alur kerja dalam sistem yang dibuat, dan mempunyai peranan menyerupai flowchart. Activity diagram juga menggambarkan alur yang terjadi saat user menjalankan sistem. Berikut activity diagram yang ada pada sistem, antara lain :

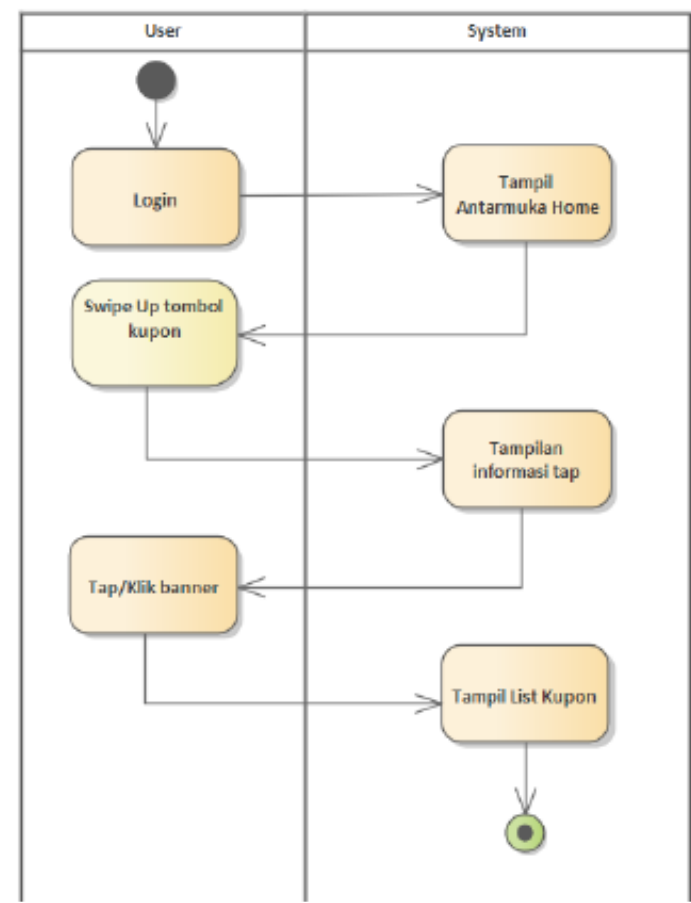

Gambar 3. Activity Diagram List Kupon

Activity diagram list kupon yang dilakukan user untuk melihat mana saja kupon yang aktif dan dapat digunakan untuk menukarnya dengan produk yang ada di kedai kopi. Dalam activity diagram ini ada beberapa aktifitas antara lain : User menggunakan account yang sudah terdaftar, Tampil Home, User swipe up layar, Tampil banner yang menginstruksikan user menekan banner, User tap banner yang ada, Tampil list kupon.

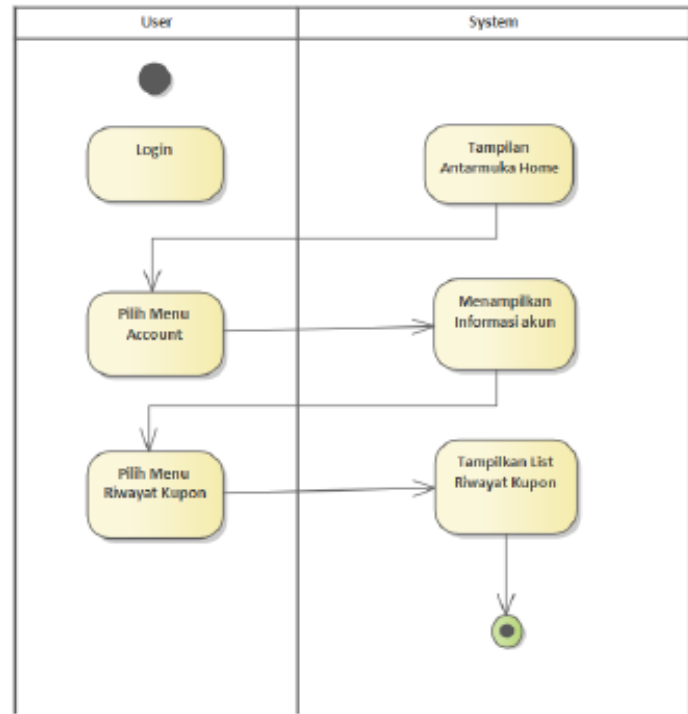

Gambar 4. Activity Diagram Riwayat Kupon

Dari hasil konsep sistem yang sudah 
dibuat maka langkah selanjutnya yaitu membuat user interface sistem untuk menggambarkan secara visual sistem yang dibuat. Untuk itu ada beberapa fitur, antara lain :

Tabel 4. Interface Login

\begin{tabular}{|c|l|}
\hline Login & \multicolumn{1}{|c|}{ Keterangan } \\
\hline 1 & $\begin{array}{l}\text { 1. Image } \\
\text { 2. Input User name } \\
\text { 3. Klik Button Masuk }\end{array}$ \\
\hline 2 & $\begin{array}{l}\text { 4. Button Lupa Password } \\
\text { 5. Button Registrasi }\end{array}$ \\
\hline 3 & $\begin{array}{l}\text { 6. Masuk Home } \\
\text { 7. Masuk Lupa Password } \\
\text { 8. Masuk Regitrasi }\end{array}$ \\
\hline
\end{tabular}

Nomer Telepon (08xxxxx)

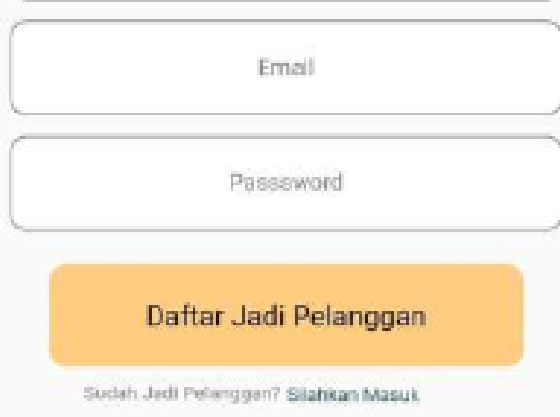

Gambar 6. Interface Registrasi

\section{Email Kamu}
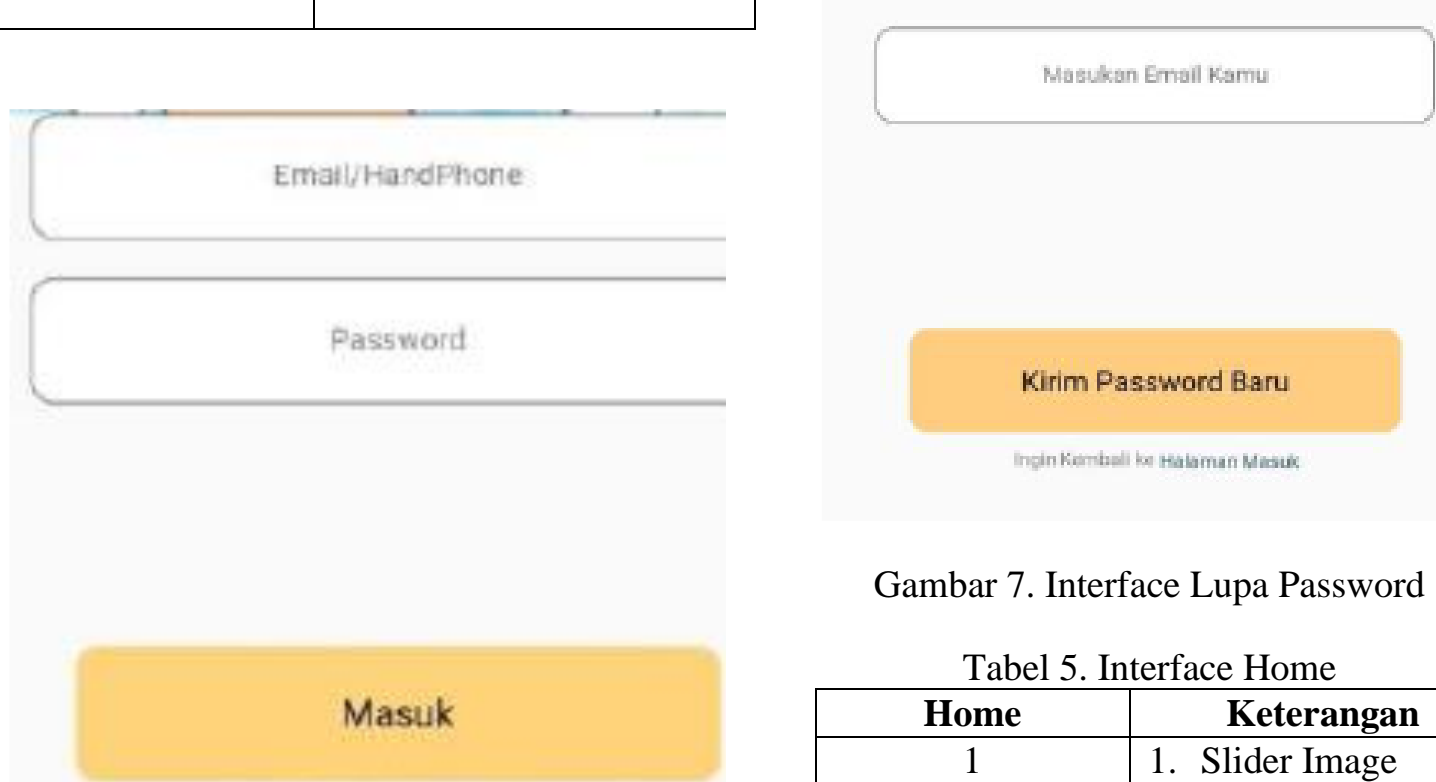

Belum Punye Alun? Ayo Dattro Sekarang

Gambar 5. Interface Login

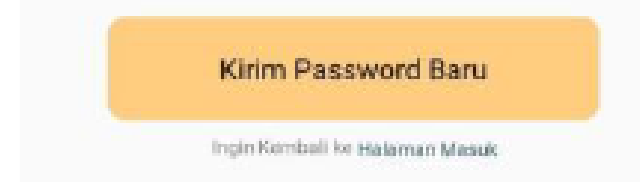

Gambar 7. Interface Lupa Password

Tabel 5. Interface Home

\begin{tabular}{|c|l|}
\hline Home & \multicolumn{1}{|c|}{ Keterangan } \\
\hline 1 & 1. Slider Image \\
& 2. Info Promo \\
& 3. Button Kupon \\
& 4. Button Home \\
& 5. Button List Menu \\
\hline & Navigasi \\
\hline 2 & 6. Masuk ke List \\
& $\begin{array}{l}\text { 7. Mupon Masuk ke Home } \\
\text { 8. Masuk ke List } \\
\end{array}$ \\
& 9. Manu kasuk Account \\
\hline
\end{tabular}




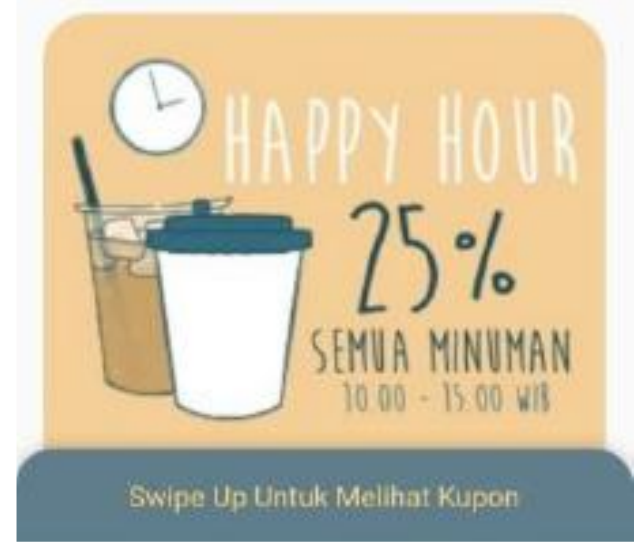

Gambar 8. Interface Home dan Promo

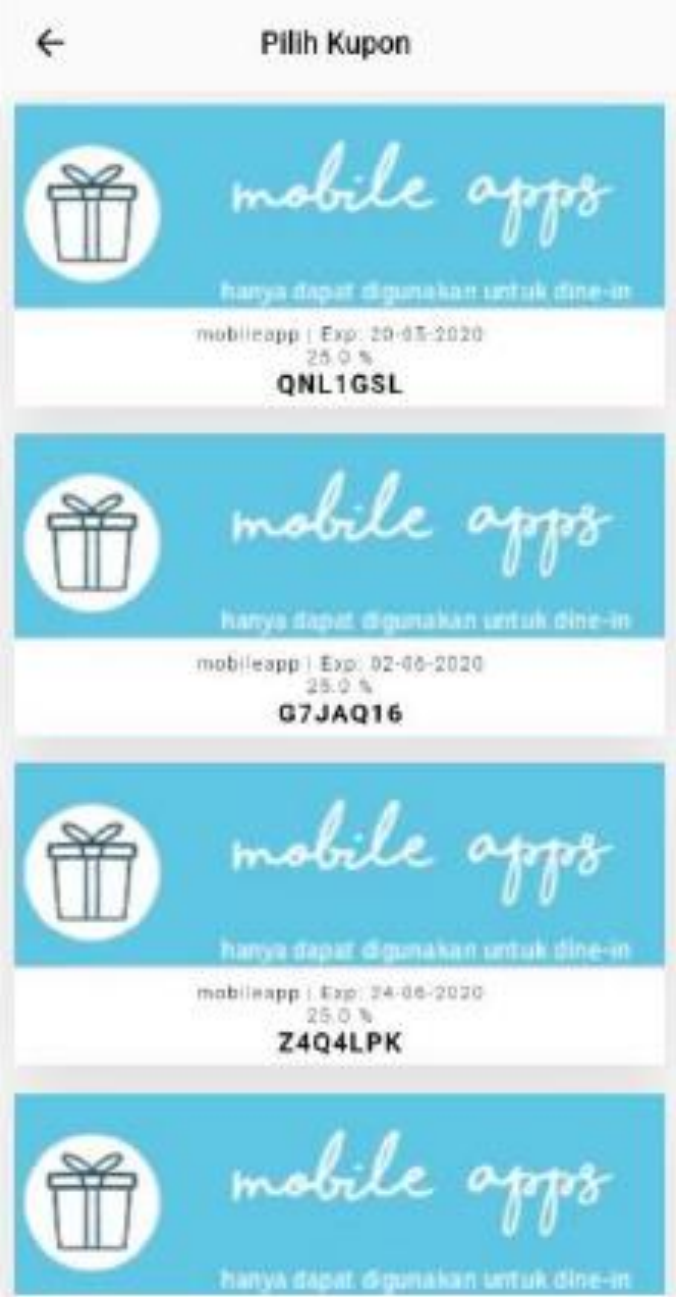

Gambar 9. Interface List Kupon
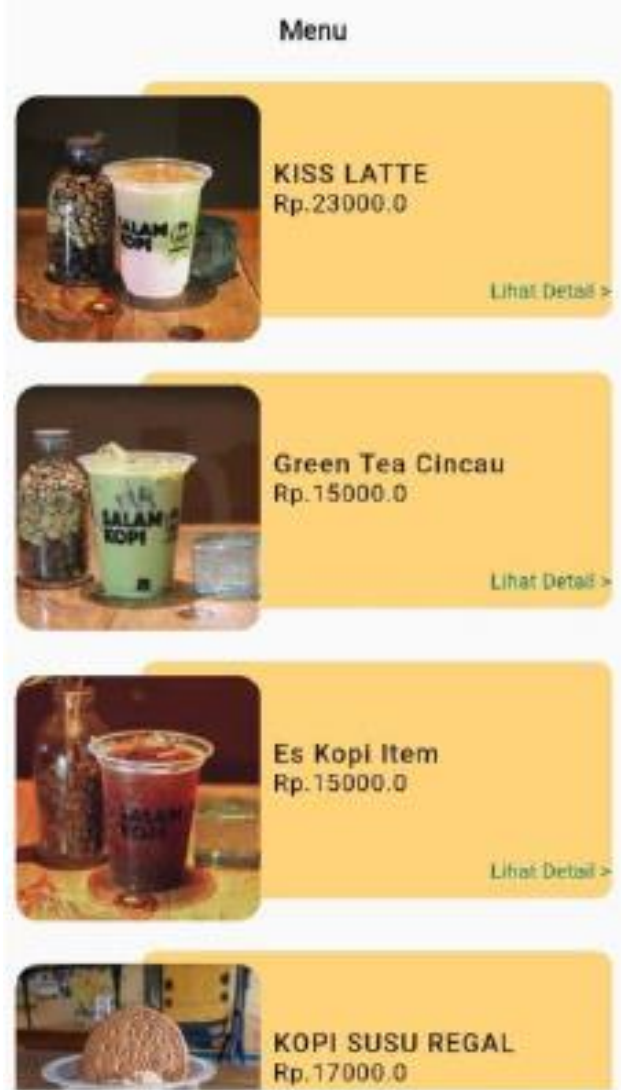

Gambar 10. Interface List Menu

(Times New Roman 11) Hasil disajikan secara sistematis, ditulis tanpa sub-bab, dan ditulis lengkap terlebih dahulu, kemudian penulis menulis hasil pembahasan. Hasil narasi berisi informasi yang diambil dari data tidak menceritakan apa adanya, tetapi menceritakan makna dari data atau informasi tersebut. Untuk keperluan klarifikasi informasi, penulis dapat menambahkan tabel, gambar, dll. Selain itu, hasil tersebut juga menyajikan item-item yang tercantum dalam tujuan penelitian atau hasil pengujian hipotesis yang diajukan beserta setiap langkah yang dilakukan untuk pengujian seperti tertulis pada bagian metode.

Pembahasan mengemukakan interpretasi hasil, pengembangan argumen dengan mengaitkan hasil, teori, dan pendapat, termasuk perbandingan dengan hasil penelitian sebelumnya. Penting juga untuk meningkatkan kemungkinan hasil penelitiannya memberikan kontribusi bagi pengembangan ilmu pengetahuan. Bagian ini tidak menulis ulang data hasil penelitian. 


\section{KESIMPULAN}

Berdasarkan hasil dari rancangan aplikasi yang dibuat dapat diambil kesimpulan sebagai berikut: Aplikasi yang dirancang dengan melakukan analisis kebutuhan yang diperlukan dalam pengembangan kedai kopi, aplikasi dapat membantu pemilik kedai kopi dalam memberikan pelayanan dan informasi kepada pelanggan mengenai produk yang dijualnya sehingga dapat bertahan dimasa pandemi seperti saat ini, bagi pelanggan dengan adanya aplikasi ini sangat membantu dalam mendapatkan informasi dan tetap bisa menikmati kopi yang diinginkan tanpa harus datang ke kedai kopi.

\section{REFERENSI}

Chandra, G. S., \& Tjandra, S. (2020). Pemanfaatan Flutter dan Electron Framework pada Aplikasi Inventori dan Pengaturan Pengiriman Barang. JOURNAL OF INFORMATION SYSTEM, GRAPHICS, HOSPITALITY AND TECHNOLOGY, 76-81, https://doi.org/10.37823/insight.v2i0 2.109 .

Fitriyani, Sudiyarti, \& Fietroh. (2020).

STRATEGI MANAJEMEN BISNIS PASCA PANDEMI COVID-19. Indonesian Journal of Social Sciences andHumanities, 8795.

Gunawan, \& Saputro, H. (2017).

PEMANFATAAN APLIKASI

MOBILE UNTUK MEMPERCEPAT PENCARIAN TEMPAT INDEKOS BERBASIS ANDROID. Jurnal Jurnal Muara Sains, Teknologi, Kedokteran, dan Ilmu Kesehatan, 85-96, http://dx.doi.org/10.24912/jmstkik.v $1 \mathrm{i} 2.1454$.
Hakim, Harefa, \& Widodo. (2019).

PENGEMBANGAN SISTEM

INFORMASI AKADEMIK

BERBASIS ANDROID

MENGGUNAKAN FLUTTER DI

POLITEKNIK. SCAN, 27-32, https://doi.org/10.33005/scan.v14i3. 1684.

Kamila, Suharyono, \& Nuralam. (2019).

PENGARUH ONLINE

CONSUMER REVIEW

TERHADAP KEPUTUSAN. Jurnal

Administrasi Bisnis, 202-211.

Kelvin, P. (2016). Perancangan Aplikasi Online Shop Berbasis Web Dan Mobile (Studi Kasus : Paper Factory). Jurnal Ilmu Komputer dan Sistem Informasi, 206.

Krisnada, \& Tanone. (2019). Aplikasi Penjualan Tiket Kelas Pelatihan Berbasis Mobile menggunakan Flutter. Jurnal Teknik Informatika dan Sistem Informasi, 281-295, https://doi.org/10.28932/jutisi.v5i3.1 865.

Marpaung, J. (2018). PENGARUH PENGGUNAAN GADGET DALAM KEHIDUPAN. Kopasta, 56-64.

Maryani, ROCHDIAN, \& SETIA. (2020). STRATEGI PENGEMBAGAN BISNIS KEDAI KOPI“AI COFFEE” DI DESA PAKEMITAN KECAMATAN CIAWI KABUPATEN TASIKMALAYA. Jurnal Ilmiah Mahasiswa AGROINFO GALUH, 739-748.

Sukamto, R. A., \& Salahuddin, M. (2016). Rekayasa Perangkat Lunak Terstruktur dan Berorientasi Objek. Bandung: Informatika. 
